\title{
Canonical Analysis for the Birth Reduction Complications after Introduction of Free Maternity Health Care Services in Kenya
}

\author{
Amos Kipkorir Langat* \\ Department of Statistics and Actuarial Science, Kenya
}

*Corresponding author: Amos Kipkorir Langat, Department of Statistics and Actuarial Science, Jomo Kenyatta University of Agriculture and Technology, Narobi, Kenya.

Received Date: December 30, 2018

Published Date: January 11, 2019

\begin{abstract}
There is a growing movement, globally and particularly in the Africa region, to reduce financial barriers to health care. Approximately 585,000 women of Reproductive age die each year from pregnancy related causes worldwide according to the World Health Organization (WHO). The purpose of the study was to examine how free maternity healthcare programme influences maternal mortality rate in Kenya. The study was guided by the following research objectives: to determine how free antenatal care influences maternal mortality rate in Bomet County; to establish how free delivery care influences the lives of others in Bomet County; to assess how free Emergency medical services influences maternal mortality rate in Bomet County and to identify how free postnatal care influences maternal mortality rate in Bomet County. The target population of this study entailed 224 mothers who attend various health maternity clinic, 20 nurses, 10 paramedics and 5 doctors. A descriptive survey research design was adopted for the study. The study focused on collecting primary and secondary data using a structured questionnaire and focus group discussions. Validity of the research instruments was determined by content and construct validity while reliability of the research instruments was determined by internal consistency method. Data collected was analyzed using both qualitative and quantitative approaches. Parametric and Nonparametric data was analyzed; such as measures of central tendency, variability and dispersion and correlation. Data were analyzed by use of and the results were presented in the table form and context. The key findings of the study revealed that free maternity care has a direct relationship to maternal mortality rate; the rate of deaths due to pregnancy related causes have reduced significantly in Kenya since the introduction of this program. The study recommended that the government should develop both long term and short term strategies in implementing free maternal healthcare services in public hospitals including creating awareness, training staff and adding more services to the program.
\end{abstract}

\section{Introduction}

The Free Maternal Health Care Initiative provides subsidized health insurance to pregnant women, giving them access to an existing range of insurance benefits that includes comprehensive maternity care with some notable exceptions such as ambulance service and post-partum family planning counselling. It is supported from the general pool of resources of the National Health Insurance Fund, which includes contributions from international partners via the health sector budget support.

According to Centre for Disease and control (CDC), the total amount spent on health care in the USA is greater than any other country in the world. Despite this, women in the USA have a greater lifetime risk of dying of pregnancy-related complications than women in 40 other countries. For example, the likelihood of a woman dying during childbirth in the USA is five times greater than in Greece, four times greater than in Germany, and three times greater than in Spain. More than two women die every day in the USA from pregnancy-related causes. African-American women are at higher risk, they are nearly four times more likely to die of pregnancy-related complications than white women. The maternal mortality ratios are higher than for women in other industrialized countries. These rates and disparities have not improved in more than 20 years. Maternal mortality ratios have actually increased from a low of 6.6 deaths per 100,000 live births in 1987 to 13.3 deaths per 100,000 live births [1-2].

In recent years, several African countries (including Burundi, Zambia, Burkina Faso, Liberia, Niger, and Sudan) have enacted policies to make deliveries and health care for mothers and children 
free in order to fulfill these mandates. Sophie Witter, Kenya's new free maternal health services policy is a potentially positive step in this direction. However, in order to comply with Kenya's international, regional, and local obligations, implementation of this policy must not override or diminish other rights provided by these frameworks. In Burundi, for example, services for pregnant women and the under-fives were introduced in 2006, and utilization appears to have increased as a result, though no formal evaluation has been undertaken. Community health worker (CHW) programmes can improve maternal health and have successfully reduced maternal mortality in both Ethiopia and Nepal. CHWs are instrumental in providing healthcare to underserved populations, particularly in rural areas, with few healthcare facilities. CHWs can improve maternal health more cost-effectively and reach more of the population if given the proper tools, such as mobile phones, bicycles and delivery kits [2-4].

In Zambia, fees were suspended for rural districts in 2006. Progress is slower in some regions than others: while every North African country has reduced maternal mortality by at least 5.5 per cent per year since 1990, only one Sub-Saharan African country has achieved an average yearly reduction of more than 4 per cent. In Burkina Faso, an $80 \%$ subsidy policy for deliveries was launched in 2006 [5]. Other countries have followed suit, though with varying target groups, and all still at the stage of being elaborated. In Rwanda a combination of community-based health insurance and performance based funding has contributed to a dramatic reduction in maternal mortality rates in Rwanda. Rwanda is on target to meet MDG 5 and reduced its maternal mortality rate from 952 to 383 per 100,000 live births between 2000 and 2008 [6].

Each household pays a fee of $\$ 2$ per year, health services are almost free and almost 91 percent of Rwandans are currently insured. Resources are pooled at the community level and packages include both preventive and curative care. Through community health insurance, women have access to family planning and antenatal care and, if they have sought antenatal care, can give birth in healthcare facilities for free. In addition to establishing communitybased health insurance, Rwanda has developed a nationwide system of contracts issued based on results performance-based financing (PBF) - which has supported dramatic improvements in maternal health. PBF involves contracts between central and local governments and healthcare facilities. The system typically measures the quantity of prevention interventions and the quality of both prevention and curative services. Good results are rewarded with increased funding for the relevant healthcare facilities and workers. Results based contracts in Rwanda have led to an increase in assisted birth deliveries and the quality of services. Additionally, the quality of antenatal care was 15 percent higher in performancebased financing clinics than in other clinics (The Partnership for Newborn, Maternal and Child Health, 2010) [7].

In Kenya, for example, various changes have been made to the user fee regime - most recently, in 2007, deliveries were announced to be free, though there is no evidence yet of implementation or impact. World health organization (WHO) estimates that more than 585,000 women of Reproductive age die each year from pregnancy related causes worldwide, $99 \%$ of these deaths occur in the less developed countries. The ratio of maternal mortality in Sub Sahara is the highest in the world estimated at 686per 100,000 live births (World Bank, 1994), if timely and appropriate obstetric care were accessed in the event of complication an estimated $75 \%$ of the above deaths could be prevented. While in many areas services simply do not exist and where they do, they are often underutilized. All women are at risk of obstetric complications; Access to adequate essential obstetric care (EOC) needs to be universal (WHO, 1998). It has been estimated by safe motherhood initiative (SMI) that 30 to 50 morbidities occur from maternal death (SMI, 2003). The rate of maternal mortality varies significantly across the world, and globally is the most inequitably distributed health indicator. One thousand women die per 100,000 live births in Sub-Saharan Africa, compared to 24 deaths per 100,000 live births in European countries (World Health Organization) [8].

Maternal deaths are caused by a wide range of complications in pregnancy, childbirth or the postpartum period. Most of these complications develop because of the pregnancy itself, and some occur where pregnancy has aggravated an existing disease. The four major killers are: severe bleeding (mostly bleeding postpartum), infections, hypertensive disorders in pregnancy (eclampsia) and obstructed labor, (World Health Organization).

Complications after unsafe abortion cause 13 per cent of maternal deaths. Globally, about 80 per cent of maternal deaths are due to these direct causes. Among the indirect causes of maternal death (20 per cent) are diseases that complicate or are aggravated by pregnancy, such as malaria, anemia and HIV. Women also die because of poor health at conception and a lack of adequate care needed for the healthy outcome of the pregnancy for themselves and their babies, (United Nations Children's Fund) [9].

Every year globally approximately 536,000 girls and women die from pregnancy-related causes - one girl or woman dies every minute. A recent Lancet study, using a revised maternal mortality methodology, estimates this number to be significantly lower 343,000 in 2008, (World Health Organization, 2007).

Proper Antenatal care would help reduce these figures by more than $50 \%$ as it allows doctors or midwives to treat and prevent potential health problems throughout the course of the pregnancy while promoting healthy lifestyles that benefit both mother and child. It has not been given the priority it deserves in Kenya. Although health sector infrastructure has grown over the past decade, many women still live at a considerable distance from health facilities, cannot afford to pay fees for antenatal services, and/or face other barriers to accessing quality care. On June 1, 2013, the Government of Kenya took action to address this problem by initiating a policy of free maternity services in all public facilities. Like many other health indicators, the burden of maternal morbidity and mortality is higher among this group, as the risk of developing pregnancy related complication and subsequent death during child birth [10$15]$.

During delivery that's when most maternal deaths occur if proper care is not observed. Over 99 per cent of maternal deaths occur in developing countries, with nearly half of these taking place in Sub-Saharan Africa. United Nations Children's Fund (2008). 
Women living in Sub-Saharan Africa have a higher risk of dying while giving birth than women in any other region of the world. For women aged 15 to 19 in Africa, giving birth is the leading cause of death. For this reason, Delivery care needs to be given special attention. The problem is driven, at least in part, by lack of access to quality maternal health services, including ante-natal, delivery, and postnatal services. Kenya has long suffered from high maternal morbidity and mortality rates. The most recent estimates set the maternal mortality rate at 488 deaths per 100,000 live births, well above the MDG target of 147 per 100,000 by 2017 [15-20]. According to Kenya National Commission on Human Rights, for every woman who dies in childbirth in Kenya, it is estimated that another 20-30 women suffer serious injury or disability due to complications during pregnancy or delivery. These high rates have persisted despite improvements in other health indicators over the past decades (Bomet: Ministry of Medical Services and Ministry of Public Health \& Sanitation, 2012). Access to skilled delivery is a particular challenge. Overall, only $44 \%$ of births in Kenya are delivered under the supervision of a skilled birth attendant, well below the target of $90 \%$ of deliveries by 2017 . Traditional birth attendants continue to assist with $28 \%$ of births, relatives and friends with $21 \%$, and in $7 \%$ of births, mothers receive no assistance at all. Success in reducing maternal mortality is dependent on and can accelerate progress on wider issues such as nutrition, education, and sexual and reproductive rights, including access to comprehensive voluntary family planning.

Emergency medical services in Africa has been a challenge thus leading to the high child mortality rates postnatal care hasn't been given the seriousness it deserves yet globally, up to 20 million girls and women a year suffer from maternal morbidities - surviving childbirth, but enduring chronic ill-health after birth, Women Deliver. Given the perspective of poverty and lack of quality maternal healthcare services in Kenya, implementation of free maternal healthcare services depends on improved hospital infrastructure, increased resources outlay, staffing and improved remuneration packages for medical staffs.

This study may enable the Government of Kenya to assess whether the programme is worthwhile to its citizens. In July 2013, it committed Sh3.8 billion to fund the free maternal health care program, with an additional Sh700 million for free access to health centers and dispensaries, Sh3.1 billion for recruitment of 30 community nurses per constituency, Sh522 million for recruitment of 10 community health workers per constituency, and Sh1.2 billion for provision of housing units to health care workers, within its overall allotment of Sh10.6 billion for health care in the 2013/14 national budget. Sh60 billion has also been allotted to county governments to be used on health, leading to a total of Sh95 billion for health overall (Communication Secretary and State House Spokesperson, 2013) [20-23].

The results of this study would also be valuable to researchers and scholars, as it would form a basis for further research. The study may improve donor's understanding on the benefits of the funds they give. Therefore, foreign and local investors would be able to inject more help to the sector through the ministry of health. The study would also bring into light the various factors that the investors and the government need to focus on when targeting provision of free maternal healthcare services. The likely outcome of this study is that lives of mothers in Bomet County have improved tremendously due to free maternal healthcare. This is expected as the free services offered by the government would enable more women to access hospitals for delivery thus ensuring successful deliveries and healthy babies.

\section{Research Material and Methods}

The reflection and collection of the literature review to this chapter attempts to present a review of various previous studies that have been undertaken in relation to free maternal healthcare services in public hospitals. Literature review will focus on free maternal healthcare services in public hospitals on live of mothers. It's a systematic identification, location scrutiny of relevant published works to gain information about research topic [23-26].

Reducing maternal mortality has seen the government and the international agencies promote maternal healthcare services. Mothers benefit from free antenatal services as they are able to freely access reproductive health education, vaccinations, pregnancy supplements, physical exam and laboratory services at no cost from public hospitals. Free Delivery care influences lives of mothers as it ensures all have access to theatre services, midwife services, and medication to enable them deliver successfully. Ortiz Captain Jose M, Free Emergency medical services influence maternal mortality rate as the wellbeing of the newborn and the mother is ensured. Free postnatal care enables mothers' access free counselling and a range of options for family planning, free gynecology service and free medication. This ensures infant mortality rate is reduced significantly [27-30].

\section{The concept of free maternal healthcare services on maternal mortality rate}

The literature suggests that free maternal healthcare services in Bomet County may influence maternal mortality rate by a host of factors such as providing free antenatal care, free delivery care, free newborn care and free postnatal care. The government's commitment to provide free maternal health services is expected to encourage more women to deliver at health facilities and to result in fewer maternal deaths. With the new policy, health facilities will be reimbursed by the government for Ministry of Health implements free maternity services nationwide every delivery that they handle, at the rate of Sh.2, 500 per birth at health centers and dispensaries, and Sh.5000 for every birth at public hospitals. This covers both normal deliveries, deliveries through caesarean, and complicated deliveries (Griffiths and Stephenson 2011). These funds are paid directly to the facilities. In addition, no fees will be charged for antenatal and post-natal care up to six weeks after delivery, or for referrals made in the case of complications related to pregnancies. All fees charged for all types of health care services at dispensaries and health centers have also been abolished [30-36].

Dugmour and Lucy, indicate that some of the greatest risk to effective capacity management rise from lack of understanding of the importance of performing the capacity management process on all resources that need to be managed for service delivery. 
Griffiths and Stephenson (2011), free antenatal care includes free vaccinations, free supplements, free laboratory services, free ultrasound, and free gynecological sessions. Free delivery care includes free midwife services, free gynecological services, free theatre services and free medication, Thaddeus and Maine (2014). Free Emergency medical services consists of services free ambulance service and free paramedic services offered to the mother in case of any emergency during pregnancy and 42 days after delivery. Postnatal care includes free counselling and a range of options for family planning, free gynecology service for the mother, free medication. If pregnant women have the knowledge on kinds of services offered by public hospital the value of implementing these services will be realized while if people do not utilize the service then it doesn't make any economic sense [37-40].

\section{Free antenatal care and maternal mortality rate}

According to the 2008-09 KDHS, less than half (47\%) of pregnant women make four or more ANC visits and only $15 \%$ access antenatal care while in the first trimester of their pregnancy. The report adds that about half (52\%) receive care before the 6 th month of pregnancy. Barnet and Lesser (2003), the median number of months of pregnancy at first visit is above the first trimester at 5.6 months. Reproductive health education is information about their reproductive health during their pregnancy period so that they can make informed decisions when to seek these services. Health education programmes during antenatal clinic should inform the women about reproductive health, knowledge related to sexuality, nutrition, family planning, malaria, HIV/AIDS etc [41,42].

Tetanus vaccinations play a big role to maternal and neonatal tetanus as it has no cure. (WHO, 2014) Claiming thousands of lives every year, Maternal and Neonatal Tetanus (MNT) is a devastating disease caused by toxins released from Clostridium tetani bacteria. With no cure, MNT is responsible for an average 110,000 deaths a year in the African Region. Once contracted, the newborn usually dies within seven days. However, MNT is entirely preventable through appropriate immunization of women of child bearing age, and through simple and basic precautionary measures in child delivery. Burns and Groove (2013), Poor hygienic conditions, lack of access to sterilized childbirth delivery tools, unhygienic practices, and limited access to health services amplify the risk for MNT during childbirth. It is for this reason that the deaths are greater than the numbers indicate.

Free pregnancy supplements given in public hospitals include folic acid and iron. The World Health Organization (WHO) recommends daily iron and folic acid supplementation for pregnant women. Doing so reduces the risk of having a pregnancy affected with spina bifida or other neural tube defects, reduces the risk of having babies with low birth weight and iron defects. The supplements also reduce the risk of maternal anemia (WHO, 2014).

Ong'ech (2009), physical Exam is well done in most hospitals that offer prenatal care in Kenya. The following are a must: weight, height and blood pressure. Vagina and cervix maybe examined for any abnormalities. A Pap smear test can be requested to check for cervical cancer. The change in the size of the cervix and uterus helps confirm the stage of your pregnancy. Pregnancy related laboratory services are free in public hospitals. Many Kenyan hospitals are well equipped to offer the best prenatal care in Kenya. The required tests for a healthy pregnancy are: Blood-blood type and the Rhesus factor. HIV test in Kenya for pregnant mothers is mandatory. This will help you especially if you are positive to start Prevention of Mother to Child Transmission program. You should get tested for STI's also. Urine tested is also carried out to establish if the kidney or bladder infections as these are not good for fetal development.

\section{Free delivery care and maternal mortality rate}

Sachs G, service provision or delivery is an immediate output of the input into the health system, such as health workforce, supplies and finances. Increased input should lead to improved services. According to Nakamara (2010), Safe Motherhood Initiative is a worldwide effort that aims to reduce the number of deaths and illnesses associated with pregnancy and childbirth. Nakamara noted that the following ways are paramount to achieving safe motherhood. Use of free Skilled birth attendance at all births, access to quality emergency obstetrical care and access to quality reproductive health care, including family planning and safe post abortion care. Kenya participated in and committed to the 2001 Abuja Declaration, pledging to commit at least $15 \%$ of the national budget to health care. Free midwife services are of importance to reduce home deliveries. According to Burns (2000), employing qualified person to monitor labor in the health facility has a great impact on reducing maternal motility. In Kenya health workers are unevenly distributed across the country with particular gaps in the North Eastern and Northern Rift provinces. Pregnant women seeking to deliver in hospitals have long suffered in the hospitals when they are unable to pay mandatory fees and many have been detained for a long period by the hospital administrators due to failure by their relatives to pay their bills or worse still majority of these women live in the urban informal settlement. After the introduction of free maternal healthcare services hospitals have reported increased numbers in maternity wards. Nurses have also reported being overburdened due to the new policy, with nearly all working overtime and as few as three (3) nurses aiding about 20 mothers at a time.

\section{Free Emergency medical services and maternal mortality rate}

Although natural, labor is a complex physiological process often lasting many hours before childbirth. Decisions made during labor can directly impact birth outcomes. For many women, clinical onset of early labor can be ambiguous, with women confusing irregular cramps of spurious labor as a sign of established labour, causing apprehension about the best time to seek health care. For a small proportion of women, labor progresses rapidly increasing the possibility of precipitous or unexpected births in the community with higher associated risks premature hospital admission for childbirth has been linked to increased risks of medical intervention due to predetermined progress milestones directed by hospital protocols as a result, laboring women are encouraged to telephone maternity wards prior to hospital attendance to remain at home until labor is established and avoid this 'cascade of interventions'. Although midwives find telephone assessment in early labor 
beneficial, women have expressed dissatisfied with telephone triaging. This leaves women wishing to go to hospital with the option of staying at home, making their own way into hospital or calling emergency services for assessment and transport.

Paramedics attend, assist and transport women who have unexpected out of hospital births however, research investigating the women in labor managed by paramedics is scarce. In one ambulance service in the east of England, Foster and Maillard, 2012 noted that only one fifth of women transported for imminent birth actually birthed before arrival to hospital, the remaining women were therefore in varying phases of first and second stage of labor. Identifying the changes from the irregular contractions of early labor to commencement of second stage requires specialized clinical skills. The challenge of adequate assessment of progress is exacerbated for women who access services not specializing in maternity care. Similar to in-hospital care of women in labor, prehospital diagnosis and assessment of progress relies on highly skilled clinical judgement recognizing specific cues. Although they are skilled emergency care practitioners, paramedics have limited education underpinning their knowledge of maternity care, with new graduates reporting lack of confidence in managing laboring women.

\section{Free postnatal care and maternal mortality rate}

Charlotte W, Pat D, Lalla T, Pyande M et al. indicate that every year in Africa, at least 125,000 women and 870,000 newborns die in the first week after birth, yet this is when coverage and programmes are at their Essential routine PNC for all mothers Assess and check for bleeding, check temperature Support breastfeeding, checking the breasts to prevent mastitis Manage anemia, promote nutrition and insecticide treated bed nets, give vitamin A supplementation Complete tetanus toxoid immunization, if required Provide counseling and a range of options for family planning Refer for complications such as bleeding, infections, or postnatal depression Counsel on danger signs and home care Essential routine PNC

According to Nakamara, all newborns should Assess for danger signs, measure and record weight, and check temperature and feeding Support optimal feeding practices, particularly exclusive breastfeeding Promote hygiene and good skin, eye, and cord care If prophylactic eye care is local policy and has not been given, it is still effective until 12 hours after birth. Promote clean, dry cord care Identify superficial skin infections, such as pus draining from umbilicus, redness extending from umbilicus to skin, more than 10 skin pustules, and swelling, redness, and hardness of skin, and treat or refer if the baby also has danger signs Ensure warmth by delaying the baby's first bath to after the first 24 hours, practicing skin-toskin care, and putting a hat on the baby Encourage and facilitate birth registration Refer for routine immunizations Counsel on danger signs and home care lowest along the continuum of care. The first day is the time of highest risk for both mother and baby. The fact that 18 million women in Africa currently do not give birth in a health facility poses challenges for planning and implementing postnatal care (PNC) for women and their newborns.

Regardless of place of birth, mothers and newborns spend most of the postnatal period (the first six weeks after birth) at home. Postnatal care (PNC) programmes are among the weakest of all reproductive and child health programmes in the region. Free postnatal care in public hospitals focuses on free counselling and a range of options for family planning, free gynecology service for the mother and free medication. WHO (2014), Half of all postnatal maternal deaths occur during the first week after the baby is born, and the majority of these occur during the first 24 hours after childbirth.1 The leading cause of maternal mortality in Africa - accounting for 34 percent of deaths - is hemorrhage, the majority of which occurs postnatal. Sepsis and infection claim another 10 percent of maternal deaths, virtually all during the postnatal period.2 HIV-positive mothers are at greater risk of postnatal maternal death than HIV-negative women.3 Access to family planning in the early postnatal period is also important, and lack of effective PNC contributes to frequent, poorly spaced pregnancies. This is a stressful time for new mothers, so emotional and psychosocial support should be available to reduce the risk of depression.

At least one in four child deaths occur during the first month of life. These deaths often take place before child health services begin to provide care, usually at six weeks for the first immunization visit. Low coverage of care in the postnatal period negatively influences other maternal, newborn, and child health $(\mathrm{MNCH})$ programmes along the continuum of care. For example, the lack of support for healthy home behaviors, such as breastfeeding, can have ongoing effects for the child in terms of under nutrition. Additionally, newborns and mothers are frequently lost to follow up during the postnatal period for prevention of mother-to-child transmission (PMTCT) of HIV.

It has been estimated that if routine PNC and curative care in the postnatal period reached 90 percent of babies and their mothers, 10 to 27 percent of newborn deaths could be averted. In other words, high PNC coverage could save up to 310,000 newborn lives a year in Africa.9 The impact on maternal survival and wellbeing would also be significant. There is now more consensus on the content of PNC.

\section{Research methods}

A cross-sectional descriptive study was used to explore influence of free maternal healthcare on the lives of mothers in Bomet County, Kenya. According to Mugenda \& Mugenda (2003), a cross-sectional descriptive study is explained as a study that entails collecting and comparing data from the phenomena at the same time of study. In addition to this, cross sectional studies are appropriate where the overall objective is to establish whether significant associations among variables exist at some point in time.

Cross sectional surveys employ an observational study that involves analysis qualitative and quantitative data collected from a population which is known as triangulation. Triangulation [12] is used to refer to all instances in which two or more research methods are employed. Thus, it might be used to refer to multimethod research in which a quantitative and a qualitative research method are combined to provide a more complete set of findings. Cross sectional surveys are important to check validity of findings by cross-checking them with another method. 
Cross sectional survey design was selected for this study due to its ability to ensure minimization of bias and maximization of the reliability of evidence collected. This study involved collection of quantitative data for objective testing and modeling while qualitative data was useful in explaining themes of descriptive information. The study used primary and secondary data that was well-versed by the objectives of this study. Data collection was done after defending the proposal. Also a Consent was sought from the Tenwek Mission Hospital using a consent letter addressed to the hospital staff. This consent letter was attached to the questionnaire. The researcher undertook data collection by giving out questionnaire for the selected respondents. 20 questionnaires were given to each of the two research assistants for data collection. The researched sort data from hospital staff who availed current hospital records. The entire data collection exercise took 2 weeks. After the data was collected, checking for errors and inconsistencies was undertaken.

Data from the questionnaire was keyed in a database programmed by SPSS and was analyzed. Key Informant focus group discussion (notes) were typed by Ms. Word capturing main respondents of participants and sorted based on the themes developed from the study objectives. Data from key informant interviews were qualitatively analyzed. All sets of data were analyzed in form of tables, charts, percentages, mean, mode etc.

Qualitative and quantitative data collection methods were used. Inferential and descriptive statistics were analyzed using SPSS while chi square test and regression were used to derive relationships that may exist between the independent and dependent variables. The mean, standard deviation, frequencies and percentages from the respondent's data were used to establish the relative importance and weight of each variable as well as the deviation of the variables from their means. This involved frequencies and cross tabulations among the selected variables.

\section{Results and Discussion}

This Section presents data that was analyzed in order to give a clear picture of the findings and for purpose of comparison with the expected findings. The purpose of the study was to examine how free maternity healthcare programme influences maternal mortality rate in Bomet County, Kenya; a case of Tenwek Mission Hospital. The data was summarized in table form and bar graph to bring out the reality at the ground. The data was collected using questionnaire and focus group discussions. The data was analyzed and classified into meaningful categories. The findings have been arranged according to the objectives.

\section{Response rate}

Out of 30 questionnaires distributed to TMH staff only 20 questionnaires were returned. This is $67 \%$ return rate. The reason for unreturned questionnaire was because some of the respondents were on leave and others were in the field and had not been back by the time of data analysis.

\section{Demographic information}

The study sought to establish information of respondents including occupation, highest education level, and work experience of the nurses, doctors and paramedics of Tenwek Mission Hospital maternity wing.

Distribution of Respondents by Occupation: The study sought to find out the relationship between respondents occupation and their opinion on influence of free maternity healthcare programme on maternal mortality rate in Bomet County, Kenya (Table 1).

Table 1: Distribution of Respondents by Occupation.

\begin{tabular}{|c|c|c|}
\hline Occupation & Respondents & \% of Total \\
\hline Nurses & 12 & $50 \%$ \\
\hline Doctors & 2 & $18 \%$ \\
\hline Paramedics & 6 & $32 \%$ \\
\hline Total & 20 & $100 \%$ \\
\hline
\end{tabular}

Table 1 revealed that $50 \%$ of the respondents were nurses who most often interacted with the patients thus indicating that the research findings would be credible as their opinion is from firsthand experience. While $18 \%$ were doctors who mostly handled complications and surgeries this indicated the credibility of the findings on causes of maternal deaths. This was followed by $32 \%$ who were paramedics indicating that result on emergency cases would be credible. This study shows that nurses are the majority in taking care of pregnant patients.

Highest education level of the respondents: The information on the respondent's level of education was sought to find if there was relationship between the highest levels of education of the staff and influence of free maternity healthcare programme on maternal mortality rate in Bomet County, Kenya (Table 2).

Table 2: : Respondent's level of education.

\begin{tabular}{|c|c|c|}
\hline Level of education & Respondents & \% of Total \\
\hline Non & 0 & $0 \%$ \\
\hline Primary & 0 & $0 \%$ \\
\hline Secondary & 5 & $10 \%$ \\
\hline College & 30 & $60 \%$ \\
\hline University & 15 & $38 \%$ \\
\hline Total & 50 & $100 \%$ \\
\hline
\end{tabular}

Table 2 revealed that none had attained below secondary education, $10 \%$ of the respondents had attained up to secondary education, $60 \%$ had attained up to college education, $30 \%$ had attained up to university education. This study shows that the information given by the respondent is likely to be credible as the respondents are all literate. This study shows that the staff attending to pregnant women are highly qualified for the task.

Table 3: Respondent's Occupation.

\begin{tabular}{|c|c|c|}
\hline Occupation & Respondents & \% of Total \\
\hline Below 5 years & 5 & $10 \%$ \\
\hline $5-10$ years & 17 & $34 \%$ \\
\hline $10-15$ years & 22 & $44 \%$ \\
\hline $15-20$ years & 4 & $8 \%$ \\
\hline Above 20 years & 2 & $4 \%$ \\
\hline Total & 50 & $100 \%$ \\
\hline
\end{tabular}

Years of Work Experience of Respondents: The information on the years of work experience of respondents was sought to find out 
if there was a relationship between the years of work experience of staff and influence of free maternal healthcare services on maternal motility rate in public hospitals. The findings were as follows (Table 3).

Table 3 showed that most staff had worked in these fields for over 5years thus were well placed to give reliable opinions regarding their views on maternal mortality rates in comparing before and after introduction of free maternal healthcare. It also

Table 4: Free Antenatal care and maternal mortality rate.

\begin{tabular}{|l|l|}
\hline Strongly Agree \\
\hline
\end{tabular}

\begin{tabular}{|c|c|c|c|c|c|c|c|}
\hline & $\begin{array}{c}\text { Strongly Agree } \\
\%\end{array}$ & Agree\% & Neutral\% & Disagree \% & $\begin{array}{c}\text { Strongly } \\
\text { Disagree \% }\end{array}$ & Mean \% & $\begin{array}{c}\text { Standard } \\
\text { Deviation } \mathrm{n} \%\end{array}$ \\
\hline $\begin{array}{c}\text { Free Tetanus vaccine ensure safe } \\
\text { delivery }\end{array}$ & $8 \%$ & $52 \%$ & $36 \%$ & $4 \%$ & 0 & 2.36 & 0.693 \\
\hline $\begin{array}{l}\text { Free supplements ensure healthy } \\
\text { mother during delivery }\end{array}$ & 0 & $44 \%$ & $30 \%$ & $16 \%$ & $10 \%$ & 2.92 & 1.007 \\
\hline $\begin{array}{l}\text { Free Laboratory testing ensure } \\
\text { safe pregnancy }\end{array}$ & $20 \%$ & $58 \%$ & $20 \%$ & $2 \%$ & 0 & 2.04 & 0.699 \\
\hline $\begin{array}{c}\text { Free physical testing ensure safe } \\
\text { pregnancy }\end{array}$ & $12 \%$ & $64 \%$ & $16 \%$ & $6 \%$ & $2 \%$ & 2.22 & 0.815 \\
\hline
\end{tabular}

Likert scale; 1= Strongly Agree, 2=Agree, 3=Not sure, 4=Disagree, $5=$ =Strongly Disagree

Source: Field Data, 2015

With regard to whether they feel Free Tetanus vaccine ensure safe delivery, there was a mean score of 2.36 on the Likert scale indicating that respondents were in agreement. This is supported by the findings which show that $52 \%$ of respondents agree to the statement. With regard to whether respondents agree Free supplements ensure healthy mother during delivery, none strongly agreed while $44 \%$ agree, $30 \%$ of the respondents are uncertain $16 \%$ disagree and $10 \%$ strongly disagree. The mean having a value of 2.92 but there were strong inconsistencies in the responses as indicated by the standard deviation of 1.007 suggesting that the views of respondents varied thus On the view of free laboratory testing ensure safe pregnancy, 20\% respondents strongly agree while 58\% agree, 20 are not certain and 2 disagree that makes the respondents in agreement. In addition to this, the mean being 2.04 and standard deviation 0.699 proves the agreement. On the other hand, $64 \%$ respondents agree and $12 \%$ respondents strongly agree free physical testing ensure safe pregnancy. The mean calculated being 2.22 and standard deviation 0.815 shows that the respondents are in agreement.

Table 5: Free Delivery care and maternal mortality rate.

\begin{tabular}{|c|c|c|c|c|c|c|c|}
\hline & $\begin{array}{c}\text { Strongly Agree } \\
\%\end{array}$ & Agree \% & Un-certain \% & Disagree \% & $\begin{array}{c}\text { Strongly } \\
\text { Disagree \% }\end{array}$ & Mean \% & $\begin{array}{c}\text { Standard } \\
\text { Deviatio n \% }\end{array}$ \\
\hline $\begin{array}{l}\text { Free midwife service leads to } \\
\text { successful deliveries }\end{array}$ & $56 \%$ & $36 \%$ & $4 \%$ & $4 \%$ & 0 & 1.56 & 0.76 \\
\hline $\begin{array}{l}\text { Free theatre services has helped } \\
\text { reduce the number of women who } \\
\text { die from pregnancy-related causes }\end{array}$ & $62 \%$ & $28 \%$ & $8 \%$ & $2 \%$ & $0 \%$ & 1.5 & 0.735 \\
\hline $\begin{array}{l}\text { Free medication ensures quick } \\
\text { recovery of the mother after } \\
\text { delivery }\end{array}$ & $30 \%$ & $38 \%$ & $12 \%$ & $16 \%$ & $4 \%$ & 2.26 & 1.175 \\
\hline
\end{tabular}

Likert scale; 1 = Strongly Agree, 2 =Agree, 3=not sure, 4=Disagree, 5=Strongly Disagree Source: Field Data, 2017 represents that most of the staff have enough experience in their careers.

\section{Free Antenatal care and maternal mortality rate}

Respondents were asked to rate the extent to which they agreed or disagreed with the various statements as related to the influence of level of free antenatal care on maternal mortality rate. A fivepoint Likert scale was used (Table 4).

From the above statistical conclusions, it can be indicated that free antenatal care is viewed as significant way of reducing maternal mortality rates in Bomet County. The maternity death database from TMH showed that MNT was responsible for an average 1,000 deaths yearly at the hospital.

This statement is supported by the focus group discussions held with the mothers at the maternity clinic at TMH who are first hand that free antenatal care enables most of them visit the clinic during pregnancy and incase of any issues they are made aware of. Also they noted that free physical testing ensures all is well during pregnancy thus ensures safe pregnancy. The mothers argued that the tetanus vaccine given was very essential as it prevented infections after delivery. They were glad it was free since preciously most of them would not afford it. They noted that free laboratory testing has gone a long way to reduce maternal mortality rate as most of them would not be able to afford it thus not get the care needed.

\section{Free delivery care and maternal mortality rate}

Respondents were asked to indicate their view on diverse factors on free delivery care in relation to how it influences maternal mortality rate (Table 5). beneficiaries of this program. On the discussions they indicated
The mean of 1.56 suggests that the response tends to be in agreement with the statement free midwife service leads to 
successful deliveries. The standard deviation of 0.76 suggests that response clusters around the mean value. When asked on whether free theatre services have helped reduce the number of women who die from pregnancy-related causes $90 \%$ of the respondents were in agreement. This is evidenced by the mean value of 1.50 and standard deviation of 0.735 that indicates the answer to be in a strong agreement. On the other hand, 30\% respondents agree, and 38\% respondents strongly agree that free medication ensures quick recovery of the mother after delivery. The mean calculated being 2.26 shows that the respondents are in agreement.

The above statistics show that free delivery care is viewed as a major factor on reducing maternal motility rate. This is indicated by majority of the respondents agreeing to the free services offered under delivery care. This is supported by the results of the focus group discussions that have many mothers strongly noting that free midwife services has helped reduce the number of women who die due to pregnancy related causes as most of them would not have been able to afford professionals during delivery. The focus group discussion conducted indicates that the women feel free theatre services has helped reduce the number of women who die from pregnancy-related causes thus significantly reduce maternal motility rate.

To support this records of the maternity database indicate that deaths due to pregnancy related issues at TMH have reduced from 20 mothers per month to 5 mothers per month since the introduction of the free maternity healthcare program. This shows that program has seen safe delivery a month middle- and low-class mothers who attend TMH as they are able to access services to ensure their wellbeing.

\section{Free emergency medical services and maternal mortality rate}

Respondents herein were asked to indicate whether Free Delivery care influenced maternal mortality rate (Table 6).

Table 6: Free Delivery care and maternal mortality rate.

\begin{tabular}{|c|c|c|c|c|c|c|c|}
\hline & $\begin{array}{c}\text { Strongly Agree } \\
\%\end{array}$ & Agree \% & Un-certain \% & Disagree \% & $\begin{array}{c}\text { Strongly } \\
\text { Disagree \% }\end{array}$ & Mean \% & $\begin{array}{l}\text { Standard } \\
\text { Deviation }\end{array}$ \\
\hline $\begin{array}{l}\text { Free paramedic service ensure safe } \\
\text { delivery }\end{array}$ & $10 \%$ & $44 \%$ & $42 \%$ & $4 \%$ & 0 & 2.4 & 0.728 \\
\hline $\begin{array}{c}\text { Free ambulance service ensure } \\
\text { successful deliveries }\end{array}$ & $6 \%$ & $40 \%$ & $46 \%$ & $8 \%$ & $0 \%$ & 2.56 & 0.733 \\
\hline $\begin{array}{l}\text { Free emergency service for } \\
\text { pregnant women ensure reduction } \\
\text { in the number of death due to } \\
\text { pregnancy related complications }\end{array}$ & $4 \%$ & $52 \%$ & $38 \%$ & $2 \%$ & 0 & 2.5 & 0.789 \\
\hline
\end{tabular}

Likert scale; 1= Strongly Agree, 2=Agree, 3=Not sure, 4=Disagree, 5=Strongly Disagree Source: Field Data, 2017

To the statement that free paramedic service ensure safe delivery half of the respondents either were uncertain and a similar number agreed. The same statistics of response applied to the respondents view on whether free ambulance service ensures successful deliveries. This is supported by the generated mean of 2.56 showing and 0.733 . Similarly when asked on whether Free emergency service for pregnant women ensure reduction in the number of death due to pregnancy related complications about half agreed and the other half were uncertain.
The above statistics shows only a few of the staff are aware of the free emergency services. This is seen as being the paramedics who actually perform this task. The other half are not aware of this service thus cannot give a positive or negative response on whether free emergency services influence maternal mortality rate. This finding is supported by focus group discussion results where most mothers confessed of neither needing the emergency services nor knowing they existed.

\section{Free postnatal care and maternal mortality rate}

Respondents were asked to give their view on whether free postnatal care influences maternal mortality rate (Table 7).

Table 7: Free postnatal care and maternal mortality rate.

\begin{tabular}{|c|c|c|c|c|c|c|c|}
\hline & $\begin{array}{c}\text { Strongly Agree } \\
\%\end{array}$ & Agree \% & Un-certain \% & Disagree \% & $\begin{array}{c}\text { Strongly } \\
\text { Disagree \% }\end{array}$ & Mean \% & $\begin{array}{c}\text { Standard } \\
\text { Deviation \% }\end{array}$ \\
\hline $\begin{array}{c}\text { Free counselling and a range of } \\
\text { options for family planning early } \\
\text { postnatal period is important to a } \\
\text { mother quick recovery }\end{array}$ & $36 \%$ & $34 \%$ & $4 \%$ & $16 \%$ & $10 \%$ & 3.3 & 0.995 \\
\hline $\begin{array}{l}\text { Free physical test done on the } \\
\text { mother postpartum ensure quick } \\
\text { recovery }\end{array}$ & $26 \%$ & $38 \%$ & $24 \%$ & $2 \%$ & $10 \%$ & 2 & 1.186 \\
\hline $\begin{array}{l}\text { Free medication given to the } \\
\text { mother ensure quick recovery }\end{array}$ & $18 \%$ & $58 \%$ & $0 \%$ & $20 \%$ & $4 \%$ & 1.5 & 0.735 \\
\hline
\end{tabular}

Likert Scale 1=Strongly Agree, 2=Agree, 3=Not sure, 4=Disagree, 5=Strongly Disagree Source: Field Data, 2015

Findings of the study on whether Free counselling and a range of options for family planning early postnatal period is important to a mother quick recovery; the mean 3.30 and standard deviation 0.995 supports the agreement by showing results to be closer to agree and strongly agree. On the other hand, the statement that free physical test done on the mother postpartum ensure quick 
recovery; The mean 2.32 supports the disagreement by showing results to be closer to agree and strongly agree the standard deviation is 1.186 as the clusters are scattered. The findings also indicate that $18 \%$ strongly agree free medication given to the mother ensure quick recovery, 58\% agree, and 24\% disagree that Free medication given to the mother ensure quick recovery. Mean of 1.50 and standard deviation 0.735 supports this agreement by indicating that respondent's answers tend to be on agreement of the statement. According to respondent's answers, it has been clearly identified that maternal motility rate has reduced due to free postnatal care (Table 8).

Table 8: Krejcie And Morgan Table (1970).

\begin{tabular}{|c|c|c|c|c|c|}
\hline $\mathbf{N}$ & $\mathbf{S}$ & $\mathbf{N}$ & $\mathbf{S}$ & $\mathbf{N}$ & $\mathbf{S}$ \\
\hline 10 & 10 & 220 & 140 & 1200 & 291 \\
\hline 15 & 14 & 230 & 144 & 1300 & 297 \\
\hline 20 & 19 & 240 & 148 & 1400 & 302 \\
\hline 25 & 24 & 250 & 152 & 1500 & 306 \\
\hline 30 & 28 & 260 & 155 & 1600 & 310 \\
\hline 35 & 32 & 270 & 159 & 1700 & 313 \\
\hline 40 & 36 & 280 & 162 & 1800 & 317 \\
\hline 45 & 40 & 290 & 165 & 1900 & 320 \\
\hline 50 & 44 & 300 & 169 & 2000 & 322 \\
\hline 55 & 48 & 320 & 175 & 2200 & 327 \\
\hline 60 & 52 & 340 & 181 & 2400 & 331 \\
\hline 65 & 56 & 360 & 186 & 2600 & 335 \\
\hline 70 & 59 & 380 & 191 & 2800 & 338 \\
\hline 75 & 63 & 400 & 196 & 3000 & 341 \\
\hline 80 & 66 & 420 & 201 & 3500 & 346 \\
\hline 85 & 70 & 440 & 205 & 4000 & 351 \\
\hline 90 & 73 & 460 & 210 & 4500 & 354 \\
\hline 95 & 76 & 480 & 214 & 5000 & 357 \\
\hline 100 & 80 & 500 & 217 & 6000 & 361 \\
\hline 110 & 86 & 550 & 226 & 7000 & 364 \\
\hline 120 & 92 & 600 & 234 & 800 & 367 \\
\hline 130 & 97 & 650 & 242 & 9000 & 368 \\
\hline 140 & 103 & 700 & 248 & 10000 & 370 \\
\hline 150 & 108 & 750 & 254 & 15000 & 375 \\
\hline 160 & 113 & 800 & 260 & 20000 & 377 \\
\hline 170 & 118 & 850 & 265 & 30000 & 379 \\
\hline 180 & 123 & 900 & 269 & 40000 & 380 \\
\hline 190 & 127 & 950 & 274 & 50000 & 381 \\
\hline 200 & 132 & 1000 & 278 & 75000 & 382 \\
\hline 210 & 136 & 1100 & 285 & 1000000 & 384 \\
\hline
\end{tabular}

The TMH maternity records show that in the last 5 years deaths due to HIV related causes during birth have gone down to zero for the patients who have religiously attended clinics and followed the guidelines given. Information gathered from the focus group discussion indicate that women find free counselling to be if importance as they are able to avoid being pregnant immediately after delivery thus have ample time to recover and gain strength. Also the women supported free physical testing as a highly influential aspect under postnatal care as they are able to detect any infections thereafter and heal appropriately. The conclusion of the discussion was that postnatal care has significantly reduced maternal motility rate.

\section{Conclusion and Recommendation}

The study revealed that there is a significant relationship between free antenatal care and maternal mortality rate in Bomet County, Kenya. Investment in free antenatal care programmes and encouragement of mothers to attend would ensure a decrease in maternal mortality rate. The roles played by vaccines and physical tests given during the antenatal period go a long way to see not only delivery of healthy babies but healthy mothers too.

The study established that there is a direct relationship between free delivery care and maternal mortality rate. Whether via virginal delivery or Caesarian Section every mother seeking to deliver must be attended to by a professional to avoid infections and worse death of mother and baby. The study identified that the nurses, doctors were well trained and had enough experience to handle the procedure.

The study also deduced that there is a relationship between free emergency medical services significantly and maternal mortality rate. This takes care of mothers on emergency situations at home who would have died due to intensive bleeding, pain or being attended to by nonprofessionals. However, the study also shows that most mothers and staff are not aware of this service offered. Failure by the government to inform women on free emergency medical services may result into underutilization of free services in lower level hospitals leading to deaths due to related circumstances.

The study established that there is a significant relationship between free postnatal care and maternal mortality rate hence women need to be encouraged to attend postnatal clinics even after safe deliveries. This would help reduce deaths due to after words complications and ensure faster healing.

The study recorded Above 50\% agreement by respondent to all question pointers the best pointer that free maternal healthcare has positively influenced reduction in maternal mortality rate.

\section{Dedication}

This research paper is dedicated to my loving wife Rose Langat and my son Ramsey Kipkirui

\section{Acknowledgement}

I acknowledge the support of the Tenwek Hospital facility for their support in sharing with me the data through the entire period of this research work. And above all God, the creator, giver of all that is good foreseeing me through this process.

\section{Conflict of Interest}

No conflict of interest.

\section{References}

1. Arhinful (2006) Effects of Free Delivery Policy on Provision and Utilization of Skilled Care at Delivery: Views from Providers and Communities in Central and Volta Regions of Ghana. 
2. Batungwanayo C, Reyntjens L (2006) L'impact du decret presidentie pour la gratuite des soins sur la qualite des services de soin de sante au Burundi. Bujumbura: i.Ministere de la Sante Publique, OMS; 2006.

3. Ministere de la Sante. Ougadougou: Direction de la Sante de la Famille (2006) Strategie nationale de subvention des accouchements et des soins obstetricaux et neonatals d'urgence au Burkina Faso.

4. Ministry of Health. Accra: Ministry of Health (2004) Guidelines for implementing the exemption policy on maternal deliveries. Report No. $\mathrm{MoH} /$ Policy, Planning, Monitoring and Evaluation-59.

5. Armar-Klemesu M, Graham W, Arhinful D, Hussein J, Asante F, et al. (2006) Aberdeen and Accra: IMMPACT; 2006. An evaluation of Ghana's policy of universal fee exemption for delivery care.

6. WHO (2015) UNICEF; UNFPA. Geneva: WHO; 2015. World Bank. Maternal mortality in 2015.

7. MoH/Health Partners (2008) Accra: MoH; 2008. Joint Ministry of Health/Partners business meeting: Aide Memoire.

8. Ministry of Health (2008) Accra: $\mathrm{MoH}$; 2008. Independent review: health sector programmed of work 2007.

9. Nakamara (2010) tracking progress in maternal, newborn and child survival: 2008 report; New York: UNICEF; 2008.

10. Gwatkin D, Rutstein S, Johnson K, Suliman E, Wagstaff A, et al. (2007) Socioeconomic differences in health, nutrition and population in developing countries: an overview. Washington, DC: World Bank; 2007.

11. Witter S, Adjei S (2007) Start-stop funding, its causes and consequences a case study of the delivery exemptions policy in Ghana. Int J Health Plann Manage 22(2): 133-143.

12. Thaddeus and Maine (2014) Funding and sustainability of the delivery exemptions scheme in Ghana.

13. Bryman (2007) Effect of delivery care user fee exemption policy on institutional maternal deaths in the Central and Volta Regions of Ghana Ghana Med J 41(3): 118-124.

14. Deganus S, Tornui J (2006) Aberdeen and Accra: IMMPACT; 2006. Impact of free delivery policy on utilization and quality of care at level B (basic obstetric care) facilities in Ghana.

15. Tornui JA, Armar-Klemesu M, Arhinful D, Penfold S, Hussein J (2007) Hospital based maternity care in Ghana: findings of a confidential enquiry into maternal deaths. Ghana Med J 41(3): 125-132.

16. Barnet, Lesser (2003) Effects of free delivery policy on provision and utilisation of skilled care at delivery: views from providers and communities in Central and Volta region.

17. Asante F, Chikwama C, Daniels A, Armar-Klemesu M (2007) Evaluating the Economic Outcomes of the Policy of Fee Exemption for Maternal Delivery Care in Ghana. Ghana Med J 41: 110-117.

18. Ortiz, Captain Jose M (2008) The Revolutionary Flying Ambulance of Napoleon's Surgeon 8: 17-25.

19. Borkowski N (2005) Organizational Behavior in Health Care.

20. USA: Jones and Bartlett Publishers Inc Bosire Boniface (2013) Kenyan Hospital Slow to Comply with Waived Maternity Fee Directive.

21. Burns N, Grove S (2007) Understanding Nursing Research: Building an Evidence based Practice. St. Louis, MO: Elsevier.

22. Cheyne H, Terry R, Niven C, Dowding D, Hundley V, et al. (2007) Should I come in now?: a study of women's early labour experiences. Br J Midwifery 15(10): 604-609.

23. McLelland GE, Morgans AE, McKenna LG (2014) Involvement of emergency medical services at unplanned births before arrival to hospital: a structured review. Emerg Med J 31: 345-350.
24. Holmes P, Oppenheimer LW, Wen S (2001) The relationship between cervical dilatation at initial presentation in labour and subsequent intervention. BJOG 108(11): 1120-1124.

25. Nolan M, Smith J (2010) Women's experiences of following advice to stay at home in early labour. Br J Midwifery 18(5): 286-291.

26. Eri TS, Blystad A, Gjengedal E, Blaaka G (2010) Negotiating credibility: first-time mothers' experiences of contact with the labour ward before hospitalisation. Midwifery 26(6): e25-30.

27. Spiby H, Green JM, Hucknal C, Richarson Foster H, et al. (2006) Labouring to better effect: studies of services for women in early labour. The OPAL study (OPtions for Assessment in early Labour). Report for National Co-ordinating Centre for NHS Service Delveryand Oragnisation R \& D (NCCSDO). National Co-ordinating Centre for NHS Service Delveryand Oragnisation R \& D (NCCSDO), York.

28. Foster T, Maillardet V (2012) Baby on the way: was an ambulance in the plan. Journal of Paramedic Practice 4(11): 649-654.

29. Corcoran N (2007) Communicating Health, Strategies for Health Promotion. London: Sage Sulochana D, Glyn N, Padam P: Utilization of postnatal care among rural women in Nepal. BMC Pregnancy and Childbirth 7:19

30. S'anchez Fuentes ML, Paine J, Elliott-Buettner B (2008) The Decriminalisation of Abortion in Mexico City: How did Abortion Rights become a Political Priority?. Gender \& Development 16(2): 345-360.

31. Creswell JW (2012) Educational Research: Planning, Conducting, and Evaluating Quantitative and Qualitative Research. Upper Saddle River NJ: Prentice Hall.

32. Charlotte W, Pat D, Lalla T, Pyande M (2005) postnatal care. Opportunities for Africa's Newborns. Bosire Bonfiace, "Kenyan Hospitals Slow to Comply with Waived Maternity Fee Directive," Sabahi. Socioeconomic Differences in Health, Nutrition and Population in Developing Countries: An Overview. Washington, DC: World Bank

33. Helen Schneider, Lucy Gilson (2000). The Impact of Free Maternal Health Care in South Africa, in Safe Motherhood Initiatives: (Reproductive Health Matters, 2000).

34. Hodgkin D (1996) Household Characteristics Affecting where Mothers Deliver in Rural Kenya.

35. Hou X, Ma N (2011) Empowering Women: The Effect of Women's Decision Making Power on Reproductive Health Services Uptake -Evidence from Pakistan. (C) World Bank.

36. Hrebiniak LG (2005) Making Strategy Work. New Jersey: Wharton School Publishing.

37. Kenya Health Sector Strategic \& Investment Plan, July 2012 June 2018 (Nairobi: Ministry of Medical Services and Ministry of Public Health \& Sanitation, 2012).

38. Makimoto K, Tsukasaki K (1999) Variations and Inconsistencies in Maternal and Child Health Indicators in Ishikawa Prefecture, Japan.

39. Nagaya K, Fetters MD, Ishikawa M, Kubo T, Koyanagi T, et al. (2000) Causes of Maternal Mortality in Japan. JAMA 283 (20): 2661-2667.

40. National Cancer Institute (2005) Theory at a Glance: A Guide for Health Promotion Practice, $2^{\text {nd }}$ Edition, NIH Publication.

41. Ngechu M (2004) Understanding the Research Process and Methods: An Introduction to Research Methods. Nairobi Act Press.

42. Nicole Bourbonnais (2013) Implementation of Free Maternal Healthcare in Kenya Health Sector Strategic and Investment Plan, MOH.

43. Krejcie RV, Morgan DW (1970) Determining Sample Size for Research Activities. Educational and Psychological Measurement. 